\title{
A prospective multi-center registry concerning the clinical performance of laparoscopic colorectal surgery using an absorbable adhesion barrier (INTERCEED ${ }^{\circledR}$ ) made of oxidized regenerated cellulose
}

\author{
Jun Watanabe ${ }^{1}$ (1) $\cdot$ Fumio Ishida ${ }^{2} \cdot$ Hideyuki Ishida $^{3} \cdot$ Yosuke Fukunaga $^{4} \cdot$ Kazuteru Watanabe $^{5} \cdot$ Masanori Naito $^{6}$. \\ Masahiko Watanabe ${ }^{6}$
}

Received: 18 March 2019 / Accepted: 15 April 2019 / Published online: 29 April 2019

(C) The Author(s) 2019

\begin{abstract}
Purpose The aim of this prospective multi-center registry was to evaluate the safety and clinical performance of INTERCEED $^{\circledR}$ in laparoscopic colorectal surgery.

Methods This study was a prospective, multi-center, single-arm registry wherein patients who received INTERCEED ${ }^{\circledR}$ in laparoscopic colorectal surgery were registered consecutively (UMIN-CTR 00001872). The primary outcome was the incidence rate of postoperative adhesive small intestinal obstruction within 6 months. The secondary outcomes were reoperation related to postoperative bleeding and anastomotic leak, surgical site infection (SSI) and anastomotic leak.

Results Between March 2012 and March 2015, a total of 202 patients were enrolled from six institutions. INTERCEED ${ }^{\circledR}$ was not applied in two patients, so 200 patients were analyzed using the full analysis set population. The incidence rate of postoperative adhesive intestinal obstruction was 1.0\% (2/200). The total SSI rate was 3.5\% (7/200), the deep incisional SSI rate was $0.0 \%(0 / 200)$, and the organ SSI rate was $0.0 \%$ (0/200). The incidence of anastomotic leak was $1.0 \%(2 / 200)$. Reoperation was performed in two cases: one for anastomotic leak and the other as cardiac surgery due to heart disease.

Conclusions Using INTERCEED ${ }^{\circledR}$ in laparoscopic colorectal surgery is safe and may be useful for preventing postoperative adhesive small intestinal obstruction.
\end{abstract}

Keywords INTERCEED ${ }^{\circledR} \cdot$ Oxidized regenerated cellulose $\cdot$ Colorectal surgery $\cdot$ Small bowel obstruction $\cdot$ Adhesion barrier

Jun Watanabe

nabe-jun@comet.ocn.ne.jp

1 Department of Gastroenterological Surgery, Yokohama City University Graduate School of Medicine, 3-9, Fukuura, Kanazawa-ku, Yokohama 236-0004, Japan

2 Digestive Disease Center, Showa University Northern Yokohama Hospital, Yokohama, Japan

3 Department of Digestive Tract and General Surgery, Saitama Medical Center, Saitama Medical University, Saitama, Japan

4 Department of Gastroenterological Surgery, Cancer Institute Hospital, Japanese Foundation for Cancer Research, Tokyo, Japan

5 Department of Surgery, NTT Medical Center Tokyo, Tokyo, Japan

6 Department of Colorectal Surgery, Kitasato University School of Medicine, Sagamihara, Japan

\section{Introduction}

Postoperative adhesion formation is the most common complication of abdominal or pelvic surgeries, affecting up to $93 \%$ of patients, although the literature notes a lack of awareness in the surgical community [1]. Certain surgical procedures are considered to carry a high risk for adhesion formation, including ovarian surgery, endometriosis surgery, tubal surgery, myomectomy and, ironically, adhesiolysis [2]. A recent systematic review was performed by Okabayashi et al. to estimate the incidence of postoperative adhesion at a second-look operation in patients undergoing abdominal surgery [3]. They found that the weighted mean rate of adhesion for all patients was 54\%. A subgroup analysis by surgical specialty showed weighted mean rates of $66 \%$ after gastrointestinal surgery, $51 \%$ after gynecologic surgery and $22 \%$ after urologic surgery. An additional analysis by surgical procedure type revealed weighted mean rates of $61 \%$ for 
cholecystectomy, $67 \%$ for total colectomy, $41 \%$ for cesarean section and $64 \%$ for myomectomy [3].

A 2014 systematic review and meta-analysis reported on the use of four adhesion prevention adjuvants (oxidized regenerated cellulose, hyaluronate carboxymethylcellulose, icodextrin liquid or polyethylene glycol gels) compared to no treatment in abdominal surgery [4]. Twenty-eight trials assessing 5191 patients were included in the meta-analysis (11 oxidized regenerated cellulose, 9 hyaluronate carboxymethylcellulose, 4 icodextrin liquid and 4 polyethylene glycol gels). Both oxidized regenerated cellulose and hyaluronate carboxymethyl cellulose significantly reduced the incidence of site-specific adhesion formation. Oxidized regenerated cellulose reduced the incidence of adhesion in gynecological surgery. However, the rate of serious adverse events was not investigated for any of the four agents.

INTERCEED $^{\circledR}$ (Johnson \& Johnson, New Brunswick, NJ, USA) is an absorbable adhesion barrier composed of $100 \%$ oxidized regenerated cellulose polysaccharide consisting of residues of glucuronic acid and glucose, with $\beta$ linkages. Macrophages/mononuclear phagocytes contain lysosomal enzymes (beta-glucuronidase and beta-glucosidase), which are capable of degrading these $\beta$ linkages. INTERCEED ${ }^{\circledR}$ is used as an adjuvant in general abdominal and gynecological operations, where it is surgically implanted after meticulous hemostasis has been achieved to reduce the occurrence of postoperative adhesion.

The clinical use of INTERCEED ${ }^{\circledR}$ has been reported in various gynecological operations for the prevention of adhesion of the peritoneal membrane and the intestinal tract [5-14]. In gastrointestinal surgery, hyaluronate carboxymethylcellulose has been used for adhesion prevention [15-20]. However, hyaluronate carboxymethylcellulose is not suited from the perspective of operability in cases of trocar-assisted laparoscopic surgery or for use in narrow spaces [21]. A previous report on the use of INTERCEED ${ }^{\circledR}$ for laparoscopic colorectal surgery was only a single-center, randomized controlled trial of a small number of cases [21].

The aim of this prospective, multi-center registry was to evaluate the safety and clinical performance of the synthetic absorbable adhesive barrier INTERCEED ${ }^{\circledR}$ in laparoscopic colorectal surgery.

\section{Materials and methods}

\section{Patients}

This study was a prospective, multi-center, single-arm registry wherein laparoscopic colorectal surgery patients who received INTERCEED ${ }^{\circledR}$ were registered consecutively at six institutions in Japan. The study protocol was approved by the ethics advisory committee and the institutional review board of each participating hospital before the study was initiated. The study was registered in the Japanese UMIN Clinical Trials Registry as UMIN000018727 [https://www.umin. ac.jp/ctr/index.htm], and all patients provided their written informed consent before registering in the study. Patients who were $\geq 20$ years of age and undergoing laparoscopic colorectal surgery were eligible for this study. The inclusion/ exclusion criteria for this study are shown in Table 1.

Table 1 The inclusion/exclusion criteria for this study

[Inclusion criteria]

Subjects who are $\geq 20$ years of age

Subjects undergoing abdominal laparoscopic surgery

Subjects willing to participate in the study and who have provided their written informed consent

Subjects in whom the use of INTERCEED ${ }^{\circledR}$ may be considered during the planned surgery

[Exclusion criteria]

Subjects requiring conversion from a laparoscopic procedure to open surgery

Patients in whom significant adhesive disease is already present at the inception of the procedure, requiring adhesiolysis, which affects the surgical time

Subjects in whom complete excision of the tumor was not achieved

Subjects with intraoperative intraperitoneal administration of chemotherapy

Subjects with severe hepatic dysfunction, renal failure, heart disease and infectious disease

Subjects in whom alternate adhesive prevention methods are used

Subjects in whom complete hemostasis could not be achieved at the location where INTERCEED ${ }^{\circledR}$ was going to be used

Subjects in whom the location where INTERCEED ${ }^{\circledR}$ was going to be used is considered infected

Subjects with a history of severe drug allergy

Subjects with an allergy to oxidized regenerated cellulose

Subjects in whom the treating physician does not feel that the application of INTERCEED ${ }^{\circledR}$ is appropriate 


\section{Procedure}

At the final step of the surgery, complete hemostasis was achieved before the use of INTERCEED ${ }^{\circledR}$. Liquids were completely removed from within the abdomen, and INTERCEED $^{\circledR}$ was cut to an appropriate size (approximately 3-5 mm larger than the site requiring adhesion prevention, such as an umbilical small incision and exfoliated surface). INTERCEED $^{\circledR}$ was placed over or between the exposed surfaces to prevent the exposed surface from adhering to the adjacent tissue. The INTERCEED ${ }^{\circledR}$ was inserted via the umbilical small incisional when applied under an umbilical small incision and via the trocar when applied to the pelvic floor. Care was taken not to wrap the anastomotic site with INTERCEED ${ }^{\circledR}$. Securing with sutures was deemed unnecessary. Immediately before abdominal closure, a single layer of INTERCEED ${ }^{\circledR}$ was applied under dry conditions. If the INTERCEED $^{\circledR}$ sheet was stained black, sufficient prevention of adhesion could not be expected, so the sheet was promptly removed, and a new one was applied after hemostasis had been achieved again. If a single sheet was insufficient to cover the entire target site, additional sheets were used, with overlap by $3-5 \mathrm{~mm}$ to ensure complete coverage of the target site. The sheets were moisturized with up to $2 \mathrm{~mL}$ of physiological saline per $3 \times 4$ in. $(7.6 \times 10.2 \mathrm{~cm})$ to ensure complete attachment to the tissue.

\section{Endpoints}

The primary outcome of this study was the incidence rate of postoperative adhesive small intestinal obstruction within 6 months. Adhesive small intestinal obstruction was defined as rehospitalization or prolonged hospitalization in a patient presenting with clinical symptoms of adhesive small intestinal obstruction requiring long tubing, along with liquid-level findings accompanied by small intestinal dilatation on an $\mathrm{X}$-ray examination. Whether or not prolonged hospitalization was required was determined by each attending physician.

The secondary outcomes were reoperation related to postoperative bleeding and anastomotic leak, surgical site infection (SSI) and anastomotic leak.

\section{Statistical analyses}

The sample size in this study was estimated based on the incidence of postoperative adhesive small intestinal obstruction. By referring to the data in the published literature, the incidence of postoperative adhesive small intestinal obstruction in this study was assumed to be $1.5 \%$. The sample size required to allow the detection of at least one patient with postoperative adhesive small intestinal obstruction in this study at a probability of $\geq 95 \%$ was calculated to be $\geq 198$. Based on this result, the target sample size in this study was set at 200 .

In this study, the data analyses of the primary and secondary outcomes were performed in the full analysis set (FAS) population, consisting of all registered patients.

Continuous values were presented using the number of subjects, mean, standard deviation, minimum and maximum. Binominal values were presented as the frequency and percentage. Clinical data including the primary outcome items were presented as the frequency, percentage and $95 \%$ confidence interval.

\section{Results}

Between March 1, 2012, and March 31, 2015, a total of 202 patients were collected from six institutions. INTERCEED ${ }^{\circledR}$ was not inserted in two patients, so 200 patients were analyzed using the FAS population (Fig. 1). The clinical characteristics of the 200 patients are presented in Table 2. The surgical procedure and outcomes are summarized in Table 3 . The site of INTERCEED ${ }^{\circledR}$ application was on the omentum under an umbilical incision (71.0\%), on the non-omentum under an umbilical incision (32.0\%) and exfoliation on the pelvic floor $(1.5 \%)$.

The incidence rate of postoperative adhesive intestinal obstruction was $1.0 \%(2 / 200)$ with a mean 6-month followup period. The total SSI rate was 3.5\% (7/200), the deep incisional SSI rate was $0.0 \%(0 / 200)$, and the organ SSI rate was $0.0 \%(0 / 200)$. The incidence of anastomotic leak was $1.0 \%(2 / 200)$. Reoperation was performed in two cases: one for anastomotic leak and the other as cardiac surgery due to heart disease. The postoperative complications are shown in Table 4.

\section{Discussion}

The incidence of postoperative adhesive small intestinal obstruction after laparoscopic colorectal surgery has been reported to be $0.4-2.5 \%$ [22-26]. In two studies with a follow-up period of $\geq 2$ years, the incidence of postoperative adhesive small intestinal obstruction was $2.4-2.5 \%$ [23, 24]. In this study, the incidence of postoperative adhesive small intestinal obstruction was 1.0\% (2/200).

There is ample evidence that INTERCEED ${ }^{\circledR}$ decreases the frequency of adhesion formation [4, 27]. This evidence has mainly been shown in gynecological surgery, but there are very limited data on its application in colorectal surgery. Three randomized controlled trials have explored the application of hyaluronate carboxymethylcellulose in colorectal surgery, finding that the frequency and extent of adhesion 
Fig. 1 Outline of the patient selection process in the present study

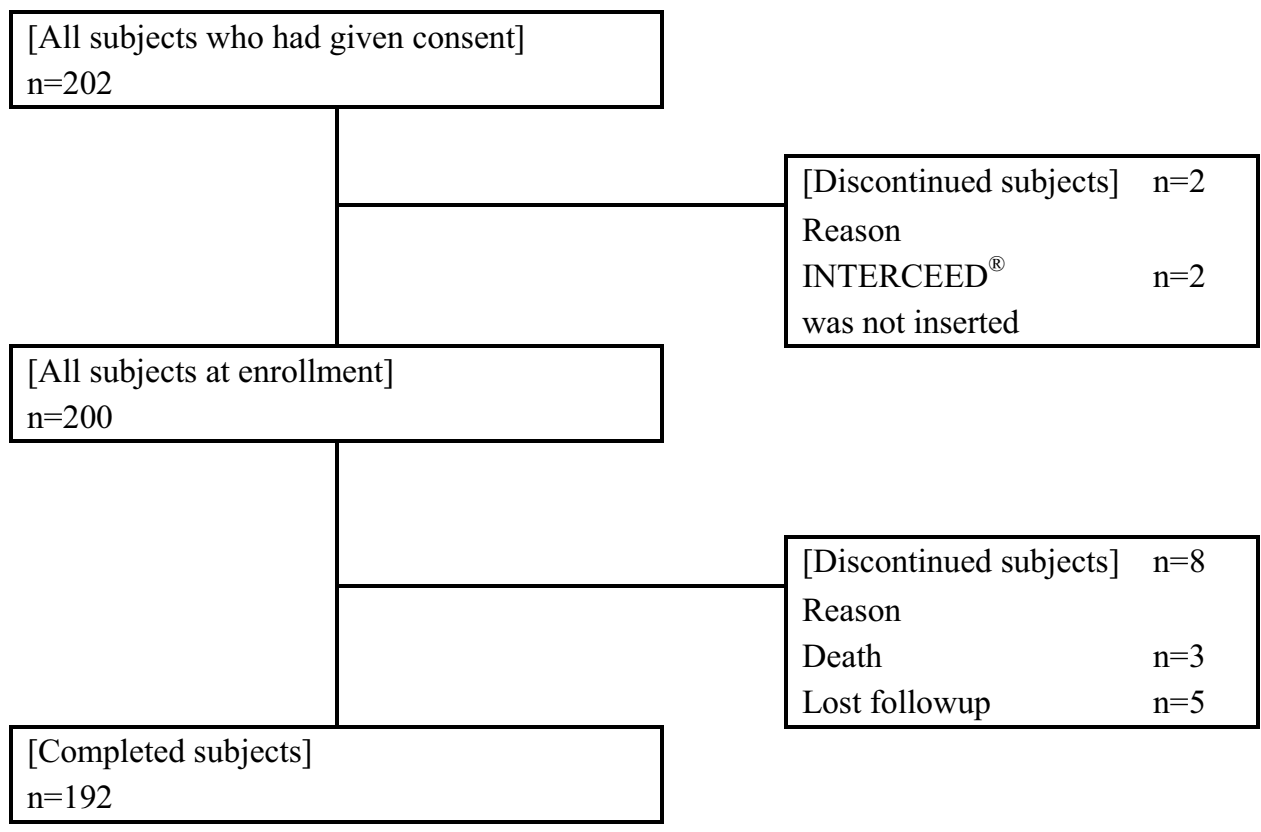

were significantly reduced in a meta-analysis [15, 16, 20]. The application of INTERCEED ${ }^{\circledR}$ in laparoscopic colorectal surgery has only been described in the report of a single randomized controlled trial with a small number of cases, and the postoperative adhesive small intestinal obstruction rate was $0.0 \%(0 / 50)$ in the INTERCEED ${ }^{\circledR}$ group versus $4.1 \%$ (2/49) in the control group [21]. The present study is the first report of a relatively large series using INTERCEED ${ }^{\circledR}$ in colorectal surgery.

Regarding any serious adverse events, the Cochrane database of systematic reviews in barrier agents for adhesion prevention after gynecological surgery reported no adverse events directly attributed to adhesion agents [27]. Five trials studied the incidence of serious adverse events after the application of hyaluronate carboxymethylcellulose in colorectal surgery [4]. The difference between the hyaluronate carboxymethylcellulose group and the control group in the incidence of serious adverse events was nonsignificant. Naito et al. [21] reported that adverse events in the INTERCEED ${ }^{\circledR}$ group of 50 cases included three cases $(6.0 \%)$ of anastomotic leakage and $1(2.0 \%)$ intra-abdominal abscess. In the present study, anastomotic leakage occurred in two cases. There were no cases of intra-abdominal abscess formation or any serious adverse events that could be directly attributed to INTERCEED ${ }^{\circledR}$. This shows that INTERCEED $^{\circledR}$ can be safely used in colorectal surgery.

Hyaluronate carboxymethylcellulose, which is mainly used in gastrointestinal surgery, has been used in laparotomy, but it was found to be unsuitable for manipulation through trocars, as is required in laparoscopic surgery [21]. In contrast, INTERCEED ${ }^{\circledR}$ is a woven sheet of oxidized regenerated cellulose that lends itself well to use in laparoscopic surgery because its softness and pliability facilitate intraoperative manipulation [21]. However, there is considered to be no significant difference between hyaluronate carboxymethylcellulose and INTERCEED ${ }^{\circledR}$ in terms of intraoperative manipulation when inserting via an umbilical small incision.

The main limitations of the present study were that it was not randomized and that it lacked a prospective casematched control group, thus failing to provide definitive proof of any benefit. As such, further multi-institution, randomized studies are needed to confirm whether or not INTERCEED ${ }^{\circledR}$ can indeed reduce the postoperative adhesive small intestinal obstruction rate in laparoscopic colorectal surgery. However, the authors believe that the findings of the present study will provide a firm foundation for future studies.

\section{Conclusion}

Using INTERCEED ${ }^{\circledR}$ in laparoscopic colorectal surgery is safe and may be useful for preventing postoperative adhesive small intestinal obstruction. A randomized controlled study is needed to further evaluate the true clinical significance of using INTERCEED ${ }^{\circledR}$ in laparoscopic colorectal surgery. 
Table 2 The clinical characteristics of the 200 patients
Mean $\pm \mathrm{SD}$ (minimum, median, maximum) $\%(\mathrm{n} / \mathrm{N})$

200

\begin{tabular}{|c|c|c|}
\hline Number of subjects & $N$ & 200 \\
\hline Age, years & Mean \pm SD & $68.6 \pm 10.8(29,69.0,92)$ \\
\hline Gender & $\%(\mathrm{n} / \mathrm{N})$ & \\
\hline Male & & $52.5 \%(105 / 200)$ \\
\hline Female & & $47.5 \%(95 / 200)$ \\
\hline Weight (kg) & Mean \pm SD & $57.92 \pm 12.58(34.0,55.75,105.3)$ \\
\hline Height $(\mathrm{cm})$ & Mean \pm SD & $159.97 \pm 9.28(140.3,160.00,183.0)$ \\
\hline BMI, $\mathrm{kg} / \mathrm{m}^{2}$ & Mean \pm SD & $22.46 \pm 3.43(14.8,22.25,34.2)$ \\
\hline Diagnosis & $\%(\mathrm{n} / \mathrm{N})$ & \\
\hline Cecal cancer & & $5.5 \%(11 / 200)$ \\
\hline Ascending colon cancer & & $13.5 \%(27 / 200)$ \\
\hline Transverse colon cancer & & $11.0 \%(22 / 200)$ \\
\hline Descending colon cancer & & $5.5 \%(11 / 200)$ \\
\hline Sigmoid colon cancer & & $27.0 \%(54 / 200)$ \\
\hline Rectosigmoid cancer & & $10.5 \%(21 / 200)$ \\
\hline Rectum cancer & & $21.5 \%(43 / 200)$ \\
\hline Crohn's disease & & $0.0 \%(0 / 200)$ \\
\hline Ulcerative colitis & & $0.0 \%(0 / 200)$ \\
\hline Other & & $7.0 \%(14 / 200)$ \\
\hline Stage grouping & $\%(\mathrm{n} / \mathrm{N})$ & \\
\hline 0 & & $2.5 \%(5 / 200)$ \\
\hline I & & $33.5 \%(67 / 200)$ \\
\hline II & & $32.5 \%(65 / 200)$ \\
\hline III & & $22.0 \%(44 / 200)$ \\
\hline IV & & $4.0 \%(8 / 200)$ \\
\hline Combination therapy, $\leq 90$ days & $\%(\mathrm{n} / \mathrm{N})$ & \\
\hline Chemotherapy & & $5.0 \%(10 / 200)$ \\
\hline Radiotherapy & & $1.0 \%(2 / 200)$ \\
\hline Immunotherapy & & $0.0 \%(0 / 200)$ \\
\hline Long term steroid medication & $\%(\mathrm{n} / \mathrm{N})$ & $1.0 \%(2 / 200)$ \\
\hline Complication/ history & $\%(\mathrm{n} / \mathrm{N})$ & \\
\hline Diabetes mellitus & & $21.5 \%(43 / 200)$ \\
\hline Hypertension & & $35.5 \%(71 / 200)$ \\
\hline Encephalopathy & & $4.5 \%(9 / 200)$ \\
\hline Angina pectoris, $\leq 30$ days & & $2.0 \%(4 / 200)$ \\
\hline Myocardial infarction, $\leq 6$ months & & $0.0 \%(0 / 200)$ \\
\hline Arterial occlusive disease & & $0.5 \%(1 / 200)$ \\
\hline Congestive heart failure, $\leq 30$ days & & $1.5 \%(3 / 200)$ \\
\hline Pneumonia at OR admission & & $0.0 \%(0 / 200)$ \\
\hline COPD & & $4.5 \%(9 / 200)$ \\
\hline Acute renal failure, $\leq 24 \mathrm{~h}$ & & $0.0 \%(0 / 200)$ \\
\hline Dialysis, $\leq 14$ days & & $0.5 \%(1 / 200)$ \\
\hline Weight loss $\geq 10 \%, \leq 6$ months & & $2.0 \%(4 / 200)$ \\
\hline Abdominal dropsy & & $0.0 \%(0 / 200)$ \\
\hline Blood coagulation disorder & & $1.5 \%(3 / 200)$ \\
\hline Smoking & & $9.5 \%(19 / 200)$ \\
\hline History of abdominal open surgery & & $30.0 \%(60 / 200)$ \\
\hline
\end{tabular}

$B M I$ body mass index, $O R$ operation room, $C O P D$ chronic obstructive pulmonary disease, $S D$ standard deviation 
Table 3 The surgical procedure and outcomes mean $\pm \mathrm{SD}$ (minimum, median, maximum) $\%(\mathrm{n} / \mathrm{N})$

\begin{tabular}{|c|c|c|}
\hline Number of subjects & $N$ & 200 \\
\hline Intervention & $\%(\mathrm{n} / \mathrm{N})$ & \\
\hline Ileocecal resection & & $7.0 \%(14 / 200)$ \\
\hline Right hemicolectomy & & $14.0 \%(28 / 200)$ \\
\hline Sigmoid resection & & $21.5 \%(43 / 200)$ \\
\hline High anterior resection & & $11.0 \%(22 / 200)$ \\
\hline Low anterior resection & & $20.5 \%(41 / 200)$ \\
\hline Other & & $26.0 \%(52 / 200)$ \\
\hline Emergency surgery & $\%(\mathrm{n} / \mathrm{N})$ & $0.0 \%(0 / 200)$ \\
\hline ASA-PS classification & $\%(\mathrm{n} / \mathrm{N})$ & \\
\hline Class 1 & & $33.5 \%(67 / 200)$ \\
\hline Class 2 & & $61.0 \%(122 / 200)$ \\
\hline Class 3 & & $5.5 \%(11 / 200)$ \\
\hline Class 4 & & $0.0 \%(0 / 200)$ \\
\hline Class 5 & & $0.0 \%(0 / 200)$ \\
\hline Length of small incision, $\mathrm{cm}$ & Mean \pm SD & $4.28 \pm 1.16(1.2,4.00,12.0)$ \\
\hline Duration of surgery, minutes & Mean \pm SD & $194.0 \pm 68.5(91,183.0,560)$ \\
\hline Blood loss, mL*1 & Mean $\pm \mathrm{SD}$ & $43.65 \pm 98.31(0.0,10.00,944.0)$ \\
\hline Blood transfusion, $\mathrm{mL}$ & Mean \pm SD & $0.2 \pm 2.1(0,0.0,30)$ \\
\hline $\begin{array}{l}\text { Drainage impl } \\
\text { ant }\end{array}$ & $\%(\mathrm{n} / \mathrm{N})$ & $58.0 \%(116 / 200)$ \\
\hline Conversion to open surgery & $\%(\mathrm{n} / \mathrm{N})$ & $0.5 \%(1 / 200)$ \\
\hline Close of mesentery & $\%(\mathrm{n} / \mathrm{N})$ & $0.5 \%(1 / 200)$ \\
\hline Colon exfoliation from splenic flexure & $\%(\mathrm{n} / \mathrm{N})$ & $16.0 \%(32 / 200)$ \\
\hline Construction of stoma & $\%(\mathrm{n} / \mathrm{N})$ & $10.5 \%(21 / 200)$ \\
\hline INTERCEED application & $\%(\mathrm{n} / \mathrm{N})$ & \\
\hline Under small incision on omentum & & $71.0 \%(142 / 200)$ \\
\hline Under small incision on non-omentum & & $32.0 \%(64 / 200)$ \\
\hline Intestinal anastomosis & & $0.0 \%(0 / 200)$ \\
\hline Retroperitoneum & & $0.0 \%(0 / 200)$ \\
\hline Exfoliation on pelvic floor & & $1.5 \%(3 / 200)$ \\
\hline Exfoliation on lymph node dissection site & & $0.0 \%(0 / 200)$ \\
\hline Exfoliation on other adhesions site & & $0.0 \%(0 / 200)$ \\
\hline Other & & $1.0 \%(2 / 200)$ \\
\hline INTERCEED removal due to stained black & $\%(\mathrm{n} / \mathrm{N})$ & $0.0 \%(0 / 200)$ \\
\hline Previous adhesion & $\%(\mathrm{n} / \mathrm{N})$ & \\
\hline Application site & & $5.5 \%(11 / 200)$ \\
\hline Non-application site & & $23.0 \%(46 / 200)$ \\
\hline Additional INTERCEED application & $\%(\mathrm{n} / \mathrm{N})$ & $0.0 \%(0 / 200)$ \\
\hline
\end{tabular}


Table 4 The incidence rate of postoperative complications
Mean \pm SD (minimum,

median, maximum)

\begin{tabular}{|c|c|c|}
\hline Number of subjects & 200 & \\
\hline Follow-up period, days & $182.8 \pm 34.6(5,185,355)$ & \\
\hline AIO & $1.0 \%(2 / 200)$ & $0.12-3.57 \%$ \\
\hline Revision surgery & $1.0 \%(2 / 200)$ & $0.12-3.57 \%$ \\
\hline Related to AIO & $0.0 \%(0 / 200)$ & $0.00-1.83 \%$ \\
\hline Related to postoperative bleeding & $0.0 \%(0 / 200)$ & $0.00-1.83 \%$ \\
\hline Related to anastomotic leak/ drainage & $0.5 \%(1 / 200)$ & $0.01-2.75 \%$ \\
\hline Other reason (cardiac surgery due to heart disease) & $0.5 \%(1 / 200)$ & $0.01-2.75 \%$ \\
\hline SSI & $3.5 \%(7 / 200)$ & $1.42-7.08 \%$ \\
\hline Superficial incisional SSI & $3.5 \%(7 / 200)$ & $1.42-7.08 \%$ \\
\hline Deep incisional SSI & $0.0 \%(0 / 200)$ & $0.00-1.83 \%$ \\
\hline Organ SSI & $0.0 \%(0 / 200)$ & $0.00-1.83 \%$ \\
\hline Anastomotic leak & $1.0 \%(2 / 200)$ & $0.12-3.57 \%$ \\
\hline Other Adverse events & $7.0 \%(14 / 200)$ & $3.88-11.47 \%$ \\
\hline Aspiration pneumonia & $1.0 \%(2 / 200)$ & $0.12-3.57 \%$ \\
\hline Paralytic ileus & $1.0 \%(2 / 200)$ & $0.12-3.57 \%$ \\
\hline Urinary tract infection & $1.0 \%(2 / 200)$ & $0.12-3.57 \%$ \\
\hline Anastomotic hemorrhage & $0.5 \%(1 / 200)$ & $0.01-2.75 \%$ \\
\hline Infective endocarditis & $0.5 \%(1 / 200)$ & $0.01-2.75 \%$ \\
\hline Prolapse of stoma & $0.5 \%(1 / 200)$ & $0.01-2.75 \%$ \\
\hline Enteritis & $0.5 \%(1 / 200)$ & $0.01-2.75 \%$ \\
\hline Clostridium difficile-associated diarrhea & $0.5 \%(1 / 200)$ & $0.01-2.75 \%$ \\
\hline Acute heart failure & $0.5 \%(1 / 200)$ & $0.01-2.75 \%$ \\
\hline Myocardial infarction & $0.5 \%(1 / 200)$ & $0.01-2.75 \%$ \\
\hline Disorder of liver function & $0.5 \%(1 / 200)$ & $0.01-2.75 \%$ \\
\hline All adverse events & $12.0 \%(24 / 200)$ & $7.84-17.33 \%$ \\
\hline Death & $1.5 \%(3 / 200)$ & $0.31-4.32 \%$ \\
\hline Aspiration pneumonia & $0.5 \%(1 / 200)$ & $0.01-2.75 \%$ \\
\hline Cancer recurrence & $0.5 \%(1 / 200)$ & $0.01-2.75 \%$ \\
\hline Sudden death & $0.5 \%(1 / 200)$ & $0.01-2.75 \%$ \\
\hline
\end{tabular}

$A I O$ adhesive intestinal obstruction, SSI surgical site infection
Funding This study was funded by Johnson \& Johnson K. K.

\section{Compliance with ethical standards}

Conflict of interest Authors declare no conflicts of interest associated with this article.

Open Access This article is distributed under the terms of the Creative Commons Attribution 4.0 International License (http://creativecommons.org/licenses/by/4.0/), which permits unrestricted use, distribution, and reproduction in any medium, provided you give appropriate credit to the original author(s) and the source, provide a link to the Creative Commons license, and indicate if changes were made.

\section{References}

1. Hirschelmann A, Tchartchian G, Wallwiener M, Hackethal A, De Wilde RL. A review of the problematic adhesion prophylaxis in gynaecological surgery. Arch Gynecol Obstet. 2012;285(4):1089-97.

2. De Wilde RL, Brolmann H, Koninckx PR, Lundorff P, Lower AM, Wattiez A, et al. Prevention of adhesions in gynaecological surgery: the 2012 European field guideline. Gynecol Surg. 2012;9(4):365-8.

3. Okabayashi K, Ashrafian H, Zacharakis E, Hasegawa H, Kitagawa Y, Athanasiou T, et al. Adhesions after abdominal surgery: a systematic review of the incidence, distribution and severity. Surg Today. 2014;44(3):405-20.

4. ten Broek RPG, Stommel MWJ, Strik C, van Laarhoven CJHM, Keus F, van Goor H. Benefits and harms of adhesion barriers for abdominal surgery: a systematic review and meta-analysis. Lancet. 2014;383(9911):48-59.

5. Azziz R. Microsurgery alone or with INTERCEED absorbable adhesion barrier for pelvic sidewall adhesion re-formation. The INTERCEED (TC7) Adhesion Barrier Study Group II. Surg Gynecol Obstet. 1993;177(2):135-9.

6. Franklin RR. Reduction of ovarian adhesions by the use of INTERCEED. Ovarian Adhesion Study Group. Obstet Gynecol. 1995;86(3):335-40. 
7. Keckstein J, Ulrich U, Sasse V, Roth A, Tuttlies F, Karageorgieva E. Reduction of postoperative adhesion formation after laparoscopic ovarian cystectomy. Hum Reprod. 1996;11(3):579-82.

8. Larsson B. Efficacy of INTERCEED in adhesion prevention in gynecologic surgery: a review of 13 clinical studies. J Reprod Med. 1996;41(1):27-34.

9. Li TC, Cooke ID. The value of an absorbable adhesion barrier, INTERCEED, in the prevention of adhesion reformation following microsurgical adhesiolysis. Br J Obstet Gynaecol. 1994;101(4):335-9.

10. Mais V, Ajossa S, Piras B, Guerriero S, Marongiu D, Melis GB. Prevention of de-novo adhesion formation after laparoscopic myomectomy: a randomized trial to evaluate the effectiveness of an oxidized regenerated cellulose absorbable barrier. Hum Reprod. 1995;10(12):3133-5.

11. Saravelos H, Li TC. Post-operative adhesions after laparoscopic electrosurgical treatment for polycystic ovarian syndrome with the application of INTERCEED to one ovary: a prospective randomized controlled study. Hum Reprod. 1996;11(5):992-7.

12. Sekiba K. Use of INTERCEED(TC7) absorbable adhesion barrier to reduce postoperative adhesion reformation in infertility and endometriosis surgery. The Obstetrics and Gynecology Adhesion Prevention Committee. Obstet Gynecol. 1992;79(4):518-22.

13. Tinelli A, Malvasi A, Guido M, Tsin DA, Hudelist G, Hurst B, et al. Adhesion formation after intracapsular myomectomy with or without adhesion barrier. Fertil Steril. 2011;95(5):1780-5.

14. Wallwiener D, Meyer A, Bastert G. Adhesion formation of the parietal and visceral peritoneum: an explanation for the controversy on the use of autologous and alloplastic barriers? Fertil Steril. 1998;69(1):132-7.

15. Becker JM, Dayton MT, Fazio VW, Beck DE, Stryker SJ, Wexner $\mathrm{SD}$, et al. Prevention of postoperative abdominal adhesions by a sodium hyaluronate-based bioresorbable membrane: a prospective, randomized, double-blind multicenter study. J Am Coll Surg. 1996;183(4):297-306.

16. Cohen Z, Senagore AJ, Dayton MT, Koruda MJ, Beck DE, Wolff BG, et al. Prevention of postoperative abdominal adhesions by a novel, glycerol/sodium hyaluronate/carboxymethylcellulose-based bioresorbable membrane: a prospective, randomized, evaluatorblinded multicenter study. Dis Colon Rectum. 2005;48(6):1130-9.

17. Fazio VW, Cohen Z, Fleshman JW, van Goor H, Bauer JJ, Wolff $\mathrm{BG}$, et al. Reduction in adhesive small-bowel obstruction by Seprafilm adhesion barrier after intestinal resection. Dis Colon Rectum. 2006;49(1):1-11.

18. Park CM, Lee WY, Cho YB, Yun HR, Lee WS, Yun SH, et al. Sodium hyaluronate-based bioresorbable membrane (Seprafilm) reduced early postoperative intestinal obstruction after lower abdominal surgery for colorectal cancer: the preliminary report. Int J Colorectal Dis. 2009;24(3):305-10.
19. Salum M, Wexner SD, Nogueras JJ, Weiss E, Koruda M, Behrens $\mathrm{K}$, et al. Does sodium hyaluronate- and carboxymethylcellulose-based bioresorbable membrane (Seprafilm) decrease operative time for loop ileostomy closure? Tech Coloproctol. 2006;10(3): 187-90 (discussion 90-1).

20. Vrijland WW, Tseng LN, Eijkman HJ, Hop WC, Jakimowicz JJ, Leguit P, Stassen LP, Swank DJ, Haverlag R, Bonjer HJ, Jeekel $\mathrm{H}$. Fewer Intraperitoneal adhesions with use of hyaluronic acidcarboxymethylcellulose membrane a randomized clinical trial. Ann Surg. 2002;235(2):193-9.

21. Naito M, Ogura N, Yamanashi T, Sato T, Nakamura T, Miura $\mathrm{H}$, et al. Prospective randomized controlled study on the validity and safety of an absorbable adhesion barrier (INTERCEED(R)) made of oxidized regenerated cellulose for laparoscopic colorectal surgery. Asian J Endosc Surg. 2017;10(1):7-11.

22. Veldkamp R, Kuhry E, Hop WC, Jeekel J, Kazemier G, Bonjer $\mathrm{HJ}$, et al. Laparoscopic surgery versus open surgery for colon cancer: short-term outcomes of a randomised trial. Lancet Oncol. 2005;6(7):477-84.

23. Taylor GW, Jayne DG, Brown SR, Thorpe H, Brown JM, Dewberry SC, et al. Adhesions and incisional hernias following laparoscopic versus open surgery for colorectal cancer in the CLASICC trial. Br J Surg. 2010;97(1):70-8.

24. Bartels SA, Vlug MS, Hollmann MW, Dijkgraaf MG, Ubbink DT, Cense HA, et al. Small bowel obstruction, incisional hernia and survival after laparoscopic and open colonic resection (LAFA study). Br J Surg. 2014;101(9):1153-9.

25. Yamamoto S, Inomata M, Katayama H, Mizusawa J, Etoh T, Konishi F, et al. Short-term surgical outcomes from a randomized controlled trial to evaluate laparoscopic and open D3 dissection for stage II/III colon cancer: Japan Clinical Oncology Group Study JCOG 0404. Ann Surg. 2014;260(1):23-30.

26. Fleshman J, Branda M, Sargent DJ, Boller AM, George V, Abbas M, et al. Effect of laparoscopic-assisted resection vs open resection of stage II or III rectal cancer on pathologic outcomes: the ACOSOG Z6051 randomized clinical trial. JAMA. 2015;314(13):1346-55.

27. Ahmad G, O'Flynn H, Hindocha A, Watson A. Barrier agents for adhesion prevention after gynaecological surgery. Cochrane Database Syst Rev. 2015(4):CD000475.

Publisher's Note Springer Nature remains neutral with regard to jurisdictional claims in published maps and institutional affiliations. 